\title{
Exposure to hydrogen sulphide and respiratory function
}

\author{
P Jäppinen, V Vilkka, O Marttila, T Haahtela
}

\begin{abstract}
A study was carried out to assess possible effects of low concentrations of hydrogen sulphide on respiratory function. The cohort comprised 26 male pulp mill workers (mean age $40 \cdot 3$, range $22-60$ years) with a daily exposure to hydrogen sulphide in the workplace, and 10 volunteers, who had asthma (three men, mean age $40 \cdot 7$, range 33 to 50 years, and seven women, mean age $44 \cdot 1$, range 31 to 61 years). The respiratory function of the pulp mill workers was monitored by measuring forced vital capacity (FVC), forced expiratory volume in one second $\left(F E V_{1}\right)$, and bronchial responsiveness after at least one day off work and at the end of a workday. Bronchial responsiveness was tested by challenge with histamine. The 10 asthmatic subjects were exposed in laboratory conditions to $2 \mathrm{ppm}$ of hydrogen sulphide for 30 minutes in an exposure chamber. Airway resistance (Raw) and specific airway conductance (SGaw) were assessed by a body plethysmograph, and the ventilatory capacities were measured with a flow volume spirometer. No significant changes in respiratory function or bronchial responsiveness related to exposure to hydrogen sulphide in the pulp mill workers were found. In the asthmatic subjects, Raw was increased by $26.3 \%$ and SGaw was decreased by $8 \cdot 4 \%$ on average after exposure to hydrogen sulphide. These changes were not statistically significant. In two subjects, however, changes were greater than $30 \%$ in both Raw and SGaw, indicating bronchial obstruction. It is con-
\end{abstract}

Enso-Gutzeit Oy, Occupational Health Centre, SF55800 Imatra, Finland

P Jäppinen

Allergy and Environment Institute in South Karelia, SF-55330 Tiuruniemi, Finland

V Vilkka, O Marttila

Department of Allergic Diseases, University Central Hospital, SF-00290 Helsinki, Finland

T Haahtela cluded that exposure for a relatively short time to hydrogen sulphide concentrations appreciably higher than those existing in ambient air do not cause noticeable effects on respiratory function.

Although sulphur dioxide is known to impair respiratory function, ${ }^{12}$ few data exist about the effects of hydrogen sulphide in this respect. Hydrogen sulphide, however, is a potential hazard of the workplace in many areas, for instance, the pulp and oil industries. Hydrogen sulphide and other organic sulphur compounds such as methyl mercaptan are emitted from pulp mills into the ambient air, causing nuisance and health effects among the general population. ${ }^{3}$ The adverse effects of high hydrogen sulphide concentrations exceeding the maximum workplace concentration of $10 \mathrm{ppm}$ are known to some extent, ${ }^{4}$ but there is a scarcity of information on possible respiratory or other effects caused by low hydrogen sulphide concentrations existing at workplaces or in ambient air around industrial sources.

We carried out a study to find out if low concentrations of hydrogen sulphide affect respiratory function. This was accomplished, firstly, by assessing the respiratory function of pulp mill workers exposed to low prevailing concentrations of hydrogen sulphide at their workplace and, secondly, by exposing voluntary subjects with bronchial asthma to a known low concentration of hydrogen sulphide under laboratory conditions.

\section{Subjects}

WORKERS EXPOSED TO HYDROGEN SULPHIDE

This group comprised 26 male pulp mill workers (mean age $40 \cdot 3$, range 22 to 60 years) with daily exposure to hydrogen sulphide usually below the maximum permitted concentration in the workplace of $10 \mathrm{ppm}$. The subjects were questioned by a nurse about their smoking habits (10 smokers) and previous allergies-namely, asthma, hay fever, atopic dermatitis (five cases). A skin prick test was performed on each subject using 12 common allergens to indicate possible atopic disposition (five atopic subjects). 
ASTHMATIC SUBJECTS FOR EXPOSURE TO HYDROGEN SULPHIDE IN THE LABORATORY

The group consisted of 10 subjects, three men (mean age $40 \cdot 7$, range $33-50$ years) and seven women (mean age $44 \cdot 1$, range $31-61$ years). They had had bronchial asthma ${ }^{5}$ for one to 13 years (mean 3.7 years) and had been using medication. Patients with severe asthma were not included in the study because a period of two days without taking drugs was recommended before the exposure to hydrogen sulphide. The stability of the asthma was assessed by monitoring PEF values twice daily at home with a peak flow meter (Spira, Respiratory Care Centre, Hämeenlinna, Finland) for at least one week before the study. The study design was accepted by the ethical committee of the hospital and consent was obtained from each subject.

\section{Methods}

The spirograms of the pulp mill workers were obtained with a dry wedge spirometer (Vitalograph Ltd, England). In the laboratory exposure test, airway resistance (Raw), specific airway conductance (SGaw), and the flow volume loop were determined by a body plethysmograph (Gould, Holland). The measurements were accomplished in that order before exposure to hydrogen sulphide and $30 \mathrm{~min}-$ utes after exposure. The values presented by Viljanen et $a l,{ }^{6}$ derived from a Finnish general population, were used as predicted normal values for forced expiratory volume in one second $\left(\mathrm{FEV}_{1}\right)$, forced vital capacity (FVC), Raw, and SGaw.

To test the bronchial responsiveness of the pulp mill workers, each subject was challenged twice; after a holiday or at least one day off from work, and at the end of a workday when there had been noticeable odour of hydrogen sulphide at the workplace. The histamine challenges were performed at the company health station near the workplace. The subjects were not exposed to accidentally high concentrations of hydrogen sulphide during the period of study (March 1987 to April 1989).

The histamine challenge test was performed by administering histamine diphosphate aerosol in ten tidal breaths with a No 40 de Vilbiss nebuliser (De Vilbiss Co, Somerset, PA), at increasing concentrations $(0 \cdot 1,0 \cdot 2,0.4,0.8,1.6$, and $3.2 \%)$, until a fall of $15 \%$ in $\mathrm{FEV}_{1}$ was achieved or the maximum histamine diphosphate concentration of $3.2 \%$ was reached. Two selected nebulisers were in use, with an output of 0.092 and $0.115 \mathrm{ml}$ aerosol per min at an airflow rate of 51 per min. The threshold concentration was designated $\mathrm{PC}_{15}$. The test was started with ten breaths from aerosol containing physiological sodium chloride. The two challenges were made at the same time of day to exclude possible confounding by diurnal variations in ventilatory function.

Possible differences between FVC, $\mathrm{FEV}_{1}$, or $\mathrm{PC}_{15}$ recorded in the two histamine challenge tests were assessed for all subjects and also for the following subgroups: (1) subjects exposed to measurable hydrogen sulphide concentrations (minimum 1 ppm); (2) those exposed workers who smoked; (3) those exposed workers who had previous allergies or bronchial asthma, and (4) the five atopic subjects with a positive reaction in the skin prick test.

The concentrations of hydrogen sulphide in the workplace were measured with an electrochemical continuous analyser (Sulfipac, Drägerwerk AG, Lübeck) by a trained hygienist just before the second histamine challenge test. The detection limit of the analyser was $1 \mathrm{ppm}$. The concentrations of hydrogen sulphide varied due to process conditions. Most measurements were between 2 and $7 \mathrm{ppm}$, with a range of 1 to $11 \mathrm{ppm}$. Even when the hydrogen sulphide concentration was below the detection limit of $1 \mathrm{ppm}$ and thus not measurable with the analyser used, a definite odour of hydrogen sulphide was still present.

For the laboratory test, two asthmatic subjects were exposed simultaneously for 30 minutes to a hydrogen sulphide concentration of $2 \mathrm{ppm}$, which is one fifth of the Finnish maximum allowable workplace concentration of $10 \mathrm{ppm}$. The exposure was performed in a tile walled sealed exposure chamber with a volume of about $10 \mathrm{~m}^{3}$. During controlled exposure, there was a constant oxygen flow of 21 per. min into the chamber, as well as a sufficient flow of hydrogen sulphide to maintain its concentration at 2 ppm. The concentration was monitored continuously with a sulphur dioxide analyser (Thermo Electron Instruments, model 43A) connected to a converter (Thermo Electron Instruments, model CDN-101) that transformed hydrogen sulphide into sulphur dioxide at $840^{\circ} \mathrm{C}$. The analyser was calibrated according to the ISO/DIS standard $6249^{7}$ with a permeation calibrator (Thermo Electron Instruments, model 360). The test gas, at a concentration of $10 \mathrm{ppm}$, was provided in laminated plastic bags by the research institute of Enso-Gutzeit Oy, and hydrogen sulphide was supplied to the chamber using a plastic tube.

For the histamine challenge test, the means and the standard errors of the means (SEMs) for the observations, and the differences between the means of observations in each group were calculated. The statistical significance of the possible differences was assessed using the $t$ test for paired samples. For the hydrogen sulphide exposure test, the statistical significance of the possible differences between the first and second measurements was assessed using the $t$ test for paired samples.

\section{Results}

WORKERS EXPOSED TO HYDROGEN SULPHIDE

Among the exposed subjects as a whole $(n=26)$, no 
Table 1 Changes in respiratory function in subjects $(n=26)$ exposed to hydrogen sulphide at their workplace

\begin{tabular}{|c|c|c|c|c|}
\hline & Before exposure (B) & After exposure $(A)$ & & \\
\hline Variable & Mean (SEM) & Mean (SEM) & Difference $(A-B)$ & p Value \\
\hline $\begin{array}{l}\text { FVC }(1) \\
\text { FVC }\left({ }^{\circ}{ }_{0} \text { predicted }\right) \\
\text { FEV }_{1}(1) \\
\text { FEV }\left({ }^{\circ}{ }_{0} \text { predicted }\right)\end{array}$ & $\begin{array}{c}4.94(0 \cdot 14) \\
94 \cdot 4(2 \cdot 2) \\
4 \cdot 10(0 \cdot 12) \\
95 \cdot 0(2 \cdot 1)\end{array}$ & $\begin{array}{c}5 \cdot 00(0 \cdot 14) \\
95 \cdot 4(2 \cdot 3) \\
4 \cdot 06(0 \cdot 12) \\
94 \cdot 1(2 \cdot 1)\end{array}$ & $\begin{array}{l}0.06 \\
1.0 \\
-0.04 \\
-0.9\end{array}$ & $\begin{array}{l}0.42 \\
0.39 \\
0 \cdot 27 \\
0 \cdot 28\end{array}$ \\
\hline
\end{tabular}

Table 2 Changes in respiratory function in asthmatic subjects $(n=10)$ exposed to 2 ppm of hydrogen sulphide for thirty minutes

\begin{tabular}{|c|c|c|c|c|}
\hline & Before exposure (B) & After exposure $(A)$ & & \\
\hline Variable & Mean (SEM) & Mean (SEM) & Difference $(A-B)$ & p Value \\
\hline 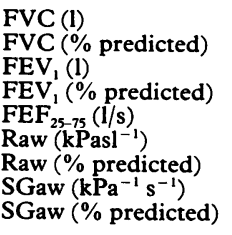 & $\begin{array}{c}3.85(0.29) \\
96 \cdot 4(5 \cdot 1) \\
3 \cdot 00(0 \cdot 23) \\
89 \cdot 9(4 \cdot 1) \\
2.58(0 \cdot 28) \\
0 \cdot 12(0 \cdot 01) \\
74 \cdot 1(9 \cdot 2) \\
3.97(0 \cdot 49) \\
208.9(25 \cdot 5)\end{array}$ & $\begin{array}{c}3.85(0.30) \\
96 \cdot 1(5 \cdot 2) \\
2.99(0.24) \\
89 \cdot 6(3.9) \\
2.62(0.31) \\
0 \cdot 14(0.02) \\
93.2(14.0) \\
3.58(0.52) \\
188.0(26.4)\end{array}$ & $\begin{array}{c}0 \\
-0.3 \\
0.00 \\
-0 \cdot 3 \\
0.03 \\
0 \cdot 03 \\
19 \cdot 1 \\
-0 \cdot 40 \\
-20.9\end{array}$ & $\begin{array}{l}0.94 \\
0 \cdot 72 \\
1.00 \\
0 \cdot 80 \\
0 \cdot 75 \\
0.06 \\
0.08 \\
0.17 \\
0.15\end{array}$ \\
\hline
\end{tabular}

statistically significant changes in pulmonary function were found, assessed by FVC and FEV (table 1), or in bronchial responsiveness, assessed by the histamine challenge test. In the first challenge, performed without exposure, $\mathrm{PC}_{15}$ was more than $3.2 \%$ in 23 cases. In the other three cases, $\mathbf{P C}_{15}$ was $2 \cdot 8 \%, 3.0 \%$, and $3.2 \%$. In the second histamine challenge, performed after hydrogen sulphide exposure, $\mathrm{PC}_{15}$ was more than $3.2 \%$ in 24 cases $(1.6 \%$ and $2.8 \%$ in the others). The subject with $P C_{15}$ of $1.6 \%$ had dyspnoea and cough after the challenge and bronchial asthma was diagnosed subsequently.

When analyses were performed on the subjects with measurable ( $1 \mathrm{ppm}$ or more) concentrations of hydrogen sulphide $(n=16)$, on smokers $(n=6)$, on workers with previous allergies $(n=4)$, and on atopic subjects $(n=5)$, no statistically significant changes in respiratory function were found.

ASTHMATIC SUBJECTS EXPOSED TO HYDROGEN SULPHIDE All subjects experienced the odour of hydrogen sulphide as very unpleasant at the start of exposure, but rapidly became accustomed to it. The subjects also sensed nasal and pharyngeal dryness at the start. Three out of 10 subjects complained of headache after exposure.

There were no notable changes in the mean FVC, $\mathrm{FEV}_{1}$, and forced expiratory flow $\left(\mathrm{FEF}_{25-75 \%}\right)$ values after exposure to hydrogen sulphide in subjects with asthma (table 2). The Raw value was slightly decreased in two and increased in eight subjects, the range of the difference being from $-5.95 \%$ to $+137.78 \%$. On average, there was an increase of
$26.3 \%$ in Raw. The mean of Raw was increased by $25 \%$ after exposure (table 2), but this increase was not statistically significant and did not result in clinical symptoms.

The SGaw value was decreased in six and increased in four subjects. On average, a decrease of $8.4 \%$ in SGaw, with a range from $-57.7 \%$ to $+28.9 \%$ occurred (table 2 ), but the change was not statistically significant. When assessing the changes in Raw and SGaw, however, it should be noted that in two subjects there were changes of over $30 \%$ in both Raw and SGaw, indicating bronchial obstruction.

\section{Discussion}

Although the effects of high concentrations of hydrogen sulphide on the body, including the respiratory system, are well known, ${ }^{4}$ virtually no information exists about the effects of low concentrations. As it is practically impossible to arrange controlled experimentation on subjects using the low hydrogen sulphide concentrations usually found in ambient air, subjects in our study were exposed to a hydrogen sulphide concentration of $2 \mathrm{ppm}$. This concentration can be produced and measured fairly accurately, and is still only a fifth of the maximum permitted workplace concentration. Furthermore, it is close to concentrations usually found in well equipped kraft pulp mills without any accidental leaks. ${ }^{8}$

Other malodorous sulphur compounds are also found in kraft pulp mills and in their vicinity, so that exposure to pure hydrogen sulphide is virtually non- 
existent. Concentrations of methyl mercaptan may be as high or even higher than those of hydrogen sulphide, ${ }^{8}$ with dimethyl sulphide and dimethyl disulphide being found at a lower concentrations. The effects of these compounds on man are not adequately known, although the effects of all malodorous sulphur compounds at the cellular level are thought to be similar.

Relatively short term exposure at the workplace did not cause noticeable effects on respiratory function of pulp mill workers. The subjects sensed the odour, but rarely had other subjective symptoms. Testing bronchial responsiveness by inhaled histamine is a well known method with good reproducibility. ${ }^{910}$ It should be noted, however, that it was not possible to assess the effects of long term exposure to hydrogen sulphide on respiratory function in this study. Furthermore, a healthy worker effect certainly exists and its magnitude cannot be estimated.

When asthmatic subjects were exposed in controlled conditions to $2 \mathrm{ppm}$ of hydrogen sulphide for 30 minutes, no significant changes in respiratory function occurred. The airway resistance increased somewhat after exposure, but it was not reflected in the subjects' clinical condition. Hydrogen sulphide concentrations in the workplace can be momentarily much higher than $2 \mathrm{ppm}$, and it is not possible to predict on the basis of this laboratory study what kind of symptoms asthmatic subjects could have at higher concentrations.

Inhalation of noxious gases is a well recognised cause of exacerbation of asthma. ${ }^{112}$ Sulphur dioxide, unlike ozone or nitrogen oxide, has a bronchoconstrictive effect of a dose dependent type, at least when inhaled during exercise. ${ }^{11}$ Sulphur dioxide and ozone increase bronchial responsiveness in both asthmatic and non-asthmatic subjects in laboratory conditions. ${ }^{1314}$ These gases are of a strongly irritant nature, which suggests that the increased airway responsiveness may be a consequence of an acute inflammatory response. ${ }^{1115}$

Malodorous sulphur compounds existing in ambient air have been shown to cause mucosal and conjunctival irritation even at low concentrations, ${ }^{3}$ and thus somewhat stronger respiratory effects were expected to occur in this study than were found. Hydrogen sulphide dissociates at neutral $\mathrm{pH}$ to a hydrogen sulphide anion, which is a strong base and thus causes mucosal irritation. ${ }^{4}$ The main effect of hydrogen sulphide on the cellular level is inhibition of the enzyme cytochrome oxidase at the end of the mitochondrial respiratory chain. ${ }^{16}$ This inhibition of the energy metabolism-probably affecting mucosal nerve endings-may explain why practically no respiratory effects were noticed in our study, either among asthmatic subjects or among pulp mill workers, despite the irritant nature of hydrogen sulphide.
Because natural gas, with a very low sulphur content, is used as the energy source by the local industry, sulphur dioxide concentrations in the ambient air of South Karelia are low; in Imatra, in the vicinity of the pulp mills, 24 hour average sulphur dioxide concentrations have been under $30 \mu \mathrm{g} / \mathrm{m}^{3} .^{17}$ It is unlikely, therefore, that exposure to sulphur dioxide in ambient air has affected the findings.

In our study, an exposure for a relatively short time to hydrogen sulphide concentrations at least 10 times higher than those usually found in the ambient air caused only minor respiratory effects among asthmatic subjects. In two out of 10 subjects, however, there were changes of over $30 \%$ in both Raw and SGaw as a sign of bronchial obstruction. It was also found that hydrogen sulphide concentrations in the workplace lower than the threshold limit value of $10 \mathrm{ppm}$ do not cause noticeable respiratory effects in non-asthmatic workers. As the material was limited, the results of our study should be considered as preliminary and further studies are warranted. To our knowledge, this is the first study of the effects of hydrogen sulphide on respiratory function utilising exposure to the gas in the laboratory.

The study was supported by grants from the Academy of Finland and the Ministry of the Environment.

1 Andersen I, Lundqvist GR, Jensen PL, Proctor DF. Human response to controlled levels of sulfur dioxide. Arch Environ Health 1974;28:31-9.

2 Archer VE, Gillam JD. Chronic sulfur dioxide exposure in a smelter. II. Indices of chest disease. J Occup Med 1978;20: 88-95.

3 Haahtela T, Vilkka V, Marttila O, Jäppinen P, Jaakkola JJK. Human health risks caused by malodorous sulfur compounds in ambient air in South-Karelia, Finland. In: Brasser LJ, Mulder WC, eds. Man and his ecosystem. Proceedings of the $8 \mathrm{th}$ world clean air congress September 1989. The Hague, the Netherlands, 1989;1:135-8.

4 Savolainen $H$. Nordiska expertgruppen för gränsvärdesdolumentation. 40. Dihydrogensulfid. Arbetarskyddsverket, Stockholm 1982. (Arbeta och Hälsa 1982:31). (In Swedish.)

5 American Thoracic Society: Chronic bronchitis, asthma and pulmonary emphysema. Am Rev Resp Dis 1962;85:762-8.

6 Viljanen A, ed. Reference values for spirometric, pulmonary diffusing capacity and body plethysmographic studies. Scand J Clin Lab Invest 1982;42(suppl 159):1-50.

7 International Organisation for Standardisation. Petroleum products-gas turbine fuels-determination of thermal oxidation stability-JFTOT method. Switzerland, 1984.

8 Kangas J, Jäppinen $P$, Savolainen $H$. Exposure to hydrogen sulfide, mercaptans and sulfur dioxide in pulp industry. $\mathrm{Am}$ Ind Hyg Assoc J 1984;45:787-90.

9 Dolovich J, Zimmerman B, Hargreave FE. In: Clark TJH, Godfrey S, eds. Asthma. 2nd ed. London: Chapman and Hall Medical, 1983:150-2.

10 Bundgaard A, Schmidt A. Reproducibility of histamine inhalation in asthmatics. Eur J Respir Dis 1986;68(suppl 43):11-3.

11 Sheppard D. Gases. In: Barnes PJ, Rodger IW, Thomson NC, eds. Asthma: Basic mechanics and clinical management. London: Academic Press, 1988:523-9.

12 Witec TJ, Schachter EN Jr, Beck GJ, Cain WS, Colice G, Leadere BP. Respiratory symptoms associated with sulfur dioxide exposure. Int Arch Occup Environ Health 1985; 55:179-83.

13 Wolff RK, Obminski G, Newhouse MT. Acute exposure of 
symptomatic steelworkers to sulphur dioxide and carbon dust: effects on mucociliary transport, pulmonary function, and bronchial reactivity. $B r J$ Ind Med 1984;41:499-505.

14 Dimeo JM, Glenn MG, Holtzman J, Sheller JR, Nadel JA, Boushey HA. Threshold concentration of ozone causing an increase in bronchial reactivity in humans and adaptation with repeated exposures. Am Rev Respir Dis 1981;124:245-8.

15 Selzer J, Scanlon PD, Drazen JM, Ingram RH Jr, Reid L. Morphologic correlation of physiologic changes caused by S02-induced bronchitis in dogs. Am Rev Respir Dis 1984; 128:790-7.

16 Nicholls P. The effect of sulphide on cytochrome aa ${ }^{3}$. Isosteric and allosteric shifts of the reduced alpha-peak. Biochim
Biophys Acta 1975;396:24-35.

17 Silakoski I, Wikström AM, Marttila O, Vilkka V, Jäppinen P, Haahtela $T$. Occurrence and measurement of malodorous sulfur compounds in ambient air in South-Karelia. In: Brasser LJ, Mulder WC, eds. Man and his ecosystem. Proceedings of the 8th world clean air congress September 1989. The Hague, the Netherlands; 1989;3:131-5.

Accepted 14 May 1990.

\section{Correspondence and editorials}

The British Journal of Industrial Medicine welcomes correspondence relating to any of the material appearing in the journal. Results from preliminary or small scale studies may also be published in the correspondence column if this seems appropriate. Letters should be not more than 500 words in length and contain a minimum of references. Tables and figures should be kept to an absolute minimum. Letters are accepted on the understanding that they may be subject to editorial revision and shortening.

The journal now also publishes editorials which are normally specially commissioned. The Editor welcomes suggestions regarding suitable topics; those wishing to submit an editorial, however, should do so only after discussion with the Editor. 